bility of my words, that "I regard experimental research in medicine as" a medical, a moral and a Christian duty towards animals, towards my fellow men and towards God."

There is so much yet to be learned chiefly, by experimental research. So many devoted lives to be saved to our country and to mankind if we only knew how! Do you wonder that I am in dead earnest?

Finally. What have the antivivisectionists themselves done to diminish sickness and save life?

$A$. In animals? Absolutely nothing.

In spite of the enormous ravages of animal diseases causing enormous suffering to animals and costing this country $\$ 215,000$,000 every year, not a single disease has had its ravages diminished or abolished as a result of anything they have done. But medical research is saving every year thousands of animals from anthrax, hog cholera, chicken cholera, Texas fever and other diseases.

$B$. In human beings? Absolutely nothing. I do not know a single disease of human beings which has had its ravages checked, abated or abolished by any work ever done by the antivivisectionists.

The only thing they have done has been to throw as many obstacles as possible in the path of those who are striving to benefit both animals and men.

This present suit is characteristic. W. W. KEEN

Emeritus Professor of Surgery, Jefrerson Medical College aNd : Major in the Medical Reserve Corps, U. S. ARMY

\section{SOME OPINIONS ON COLLEGE PHYSICS TEACHING}

Originally the whole of science, physics has come by specialization to have for a central interest the relations of energy to matter, motion, hea and electricity; it lies, not sharply bounded, among astronomy, chemistry, the biological and earth sciences, and their applications in engineering and agriculture. From it all these draw fundamental data, and from it new branches continually develop. The history of this development is very interesting and instructive; it forms one phase of the intellectual development of humanity, and should be known to all students whose interests are at all higher than the bread-and-butter level.

It has been said that science is common sense. That is incompletely true; for common sense results from common experience, and can hardly deal with uncommon or new situations. From this arises one of the diffculties which to many people make physics a repulsive subject. It deals with facts of all sorts, from bearing friction and the flow of water in pipes to the flight of wireless waves and the rotation of nebulæ, and has to adopt a viewpoint which can not be that of common experience; for observations on most of this vast range are not commonly made, and not by common people. Newton's three laws of motion, for example, are not expressions of common sense; otherwise they would not have been reserved for Newton to state. They are known not to be in conflict with common experience; they include it; but the average person has not had the uncommon astronomical and laboratory experiences necessary for their discovery or appreciation. Hence the mechanics based on them seems stale and dry, metaphysical, out of connection with experience.

The subject of physics being thus vast, not ' clearly defined and to a certain extent removed from common experience, only a part of it can be taught in elementary courses. What this part shall be has to be decided with an eye on two things; it must seem worth while to the student, and it must expand his horizon of experience, so that the great general laws which have been discovered shall seem to him to spring naturally from the behavior of matter. To seem worth while to a student, the subjectmatter of a course must build upon what he already knows, and must have evident bearing upon the problems which he knows he will have to solve. He has had experience with crow- 
bars, boats, automobiles, telephones; it is wise to start out with this knowledge and unify it; he knows he must solve problems in practise, with pulleys, hydraulic rams, cameras or wireless instruments; he should see that his physics is leading to an ability to do these things.

In mass teaching, such as teaching in most American institutions must be, the aim of the teacher must be at the average man in the class. The ground covered, the rate at which it is covered, and its relative difficulty, must depend on the ambitions of this average man; these can be determined only by "feeling of" the class, and change from year to year. While this matter is one too extensive for treatment here, it should be noted that the problem is by no means a simple one; the teacher is only one element in the competition of which the student is the center, and he and his course can not always hope to master the student's attention against the intense pressure of fraternities, games, "Wein, Weiber und Gesang." To play a part in this competition and win any real success implies that the teacher must realize the situation and be ready himself to exert a sensible pressure. The easygoing notion that they may take it or leave itthat's their business-is as much out of place in the teaching of physics as it is in the selling of hair-wash and automobiles. I believe that college administrations are more at fault in their ill appreciation of this than are college teachers, though something can be said on both sides.

The teaching methods usually adopted for elementary work are lectures, text-book study with problem-solving, and laboratory work. Each has its peculiarities, its limitations and difficulties.

Physics lectures are carried on with experiments, qualitative or semi-quantitative, which the audience observes under the guidance of the speaker, without having to supply skill or initiative. This method is the only one for the exposition of original research or recent progress; many experiments are valuable when taken up thus and less so otherwise; the more or less passive attitude of the audience is the great weakness. It does very well as an easy way for beginning or general classes; pedagogical tricks, like written notes and quizzes, help to diminish somewhat the somnolence due to passivity. However, every lecture is probably more valuable to the speaker than to any of his hearers. Every teacher who uses this method, and requires the completion of written notebooks on the course, should read some of these notebooks with some care. $\mathrm{He}$ will learn something about the value to the audience of his own lectures.

The presentation of lecture experiments is often weakened by inattention to the details of lighting. An experiment which only a few of the audience can see is wasted, however it may please the lecturer, for it is his business to "get it over" just as much as if there were footlights between him and his hearers. It is not enough to set the apparatus up-it must go; and it is not enough that the experiment go-the audience must see it; and weak lighting of the critical point, glitter and glare on glass surfaces, supports in the way, etc., sometimes hinder the audience from seeing. While the experiment is being tried out in advance the lecturer should view it from the audience space and from the most disadvantageous points, to correct such weaknesses.

The combined recitation and laboratory method makes greater demands on the members of a class than the lecture method. I do not believe that any student should be allowed to take a purely text-book course in elementary physics; the laboratory should invariably accompany the recitation.

The study of a book, the solution of problems, the answering of questions, give play to both originality and skill; book explanations and descriptions of experiments not only lead to an understanding of work performed in the laboratory, but they bring in order before the mind the results of experiments and observations which only a favored few can ever directly know because of difficulty, expense or length of time required.

The objects of laboratory work are two; to illustrate (not demonstrate) the laws of nature, and to teach the technique of experiment. This latter is apparently only secondary, but 
without it experiments illustrate rather the fallibility of human nature than the laws of nature. Much time and effort must be given to it. It was formerly a common notion that in the laboratory the student should by himself rediscover the laws of nature, doing in a few youthful work periods what during two thousand years the greatest minds only gradually accomplished. Nobody thinks of that now; the laws of machines, of motion, of heat and electricity can only be illustrated, not discovered, in the student laboratory. The beginner has not only to make the illustrative observations, he must learn how to make them. The technique of observation is as real as that of the shop; just as in wood shop or forge or machine room the ways of handling materials and metals which experience has proved good are not only taught but insisted on, so the technique of the laboratory must be enforced; the setting up of apparatus, the making of measurements, the interpretation of the measurements, all these must be done according to good ways developed by experience. Hence there must be rather explicit directions for work placed in the hands of the student, dealing not merely with apparatus in general, but with the apparatus of the laboratory where the work is done. It is justly to be questioned whether general laboratory manuals are a success; were all laboratories equipped with the same patterns of apparatus it might be possible to write a manual which would serve them all; as the case is, different laboratories have such different equipments, inherited and constructed, that the detailed directions which the beginner must have are unique in each institution. This does not mean, of course, that manuals can not be written in book form (though I hold the loose-leaf system better, as more flexible), but that the book which fits the conditions of one place can hardly fit those of another.

Not only is the technique of observation the result of a long historical development; equally so is the technique of the interpretation of observations when made. For the elementary laboratory the experiment directions should be laid out with this in mind, and good methods of reduction and a reasonable standard of accuracy insisted on. Of course the degree of accuracy can not be very high-usually a tenth of a per cent. is very good for student work, and sufficient, in well-planned experiments, for the illustrations desired. Better than this is hardly to be expected, as the apparatus for beginners can not have many refinements, and must also be fairly fool-proof, if the staff is not to spend most of its time making repairs. For this degree of accuracy and for the purposes of illustration careful sliderule calculations and careful use of plotting paper are excellent in most cases; I have not found that the average student is any more able to learn the accurate use of these materials than he is of apparatus, unless he is obliged to take the pains, and taught how.

Since the object of the laboratory work is the illustration of the laws of nature, the interpretation of the results should not be made difficult by clouds of calculation, myriads of curves or apparatus planned badly for the purpose in hand. I have sometimes been obliged to force students through laboratory directions subject to these drawbacks, and the reading of their reports has driven me to the belief that simple experimental methods, direct and wellplanned computations and the use of curves when curves are the shortest way to bring out the facts, are what they need to be taught with great pains. In the elementary laboratory busy work has no place. Particularly, I am sure that in some cases where students are forced to compute results by the method of least squares the labor is worse than wasted, as certain basic assumptions of the application are not justified in the conditions of the observations. The existence of such cases was pointed out in Nature a good many years ago; Merriman has dealt with their theory and computation; a glance at his paper will convince any one that such treatment has no place in the elementary laboratory.

When the student has got along in his knowledge of laboratory technique he should be set at problems which involve reading and advanced observation, but this should in general be called research only if the undergraduate is 
to be flattered thereby. I am of the opinion that the use of precision instruments in the repetition of classical experiments would be for the advanced undergraduate much better than a good deal of the "research" which he carries on with a man at his ellbow to show him how, and perhaps not worse for the teacher. The study and mastery of the original articles of a series of the classical experiments, and the supervision of the experimental work, would be highly valuable for any teacher of physics.

In these days of rising costs the teacher of physics, like all the rest, should have at heart the problem of waste in his administration. As I once heard Professor B. K. Emerson say to a student, in the course of a mild rebuke for mishandling a crystal specimen, a collection is meant to be used up, but not to be destroyed; and so with apparatus. I think that the best means to meet this problem is to hold every student personally responsible for the apparatus which is intrusted to him, by keeping a personal account with him. The plan of assessing all students at a flat rate for laboratory expenses, no matter who does damage, used to seem to me little better than highway robbery on the part of the laboratory, and I have no doubt that students feel the same now. The individual account is some trouble, to be sure, but it makes each man feel responsible and act carefully, as I can testify from experience.

WORCESTER, MASS.

\section{WILLARD J. Fisher}

\section{SCIENTIFIC EVENTS}

THE RAMSAY MEMORIAL FUND

AFTER the death of Sir William Ramsay in July, 1916, a memorial meeting was held in London to commemorate his thirty-five years of service in physical and chemical sciences, education and public welfare. As was noted in Solence at the time, the gathering of distinguished men, under the chairmanship of Lord Rayleigh, decided

1. To raise a substantial fund as a memorial to Sir William; and

2. To use-such fund for the establishment of (a) Ramsay Research Fellowships, tenable wherever necessary facilities might be available, and a

(b) Ramsay Memorial Laboratory of Engineering Chemistry at the University of London, where Sir William served twenty-six of his most fruitful years of activity.

A committee of prominent men in the physical and chemical sciences in Great Britain, including the leaders of the Coalition government and Ambassadors then accredited to the Court of St. James, was later organized. Through this general organization, committees were organized in Australia, Canada, Chile, Denmark, Holland, India, Italy, Japan, New Zealand, Spain, Switzerland and the United States. Correspondence with men of science indicate the formation of National Committees also in China, France and Sweden, and perhaps Russia.

The sum set out to be raised was $£ 100,000$. To date something over $£ 300$ have been contributed by residents of the United States.

The merits of the objects of this fund are obvious. The recognition of a man who made so many valuable contributions to our knowledge and who won so many friends through his wonderful friendly sympathy and erudition appeals especially to American men and women.

The committee expects some generous contributions and will welcome the receipt of other large gifts, but it hopes especially to have a great number of small subscribers. The receipt of checks, postal orders, or cash, for one dollar or over, sent to the Ramsay Memorial Fund Association, 50 East 41st St., New York City, will be promptly acknowledged.

\section{UNITED STATES CONMITTEE FOR THE RAMSAY MEMORIAL FUND \\ Walter Hines Page, Marston T. Bogert, Vice-president Chas. F. Chandler, Charles Baskerville, Francis W. Clarke, Chairman Wm. D. Coolidge, \\ Wm. J. Matheson, John H. Finley, Treasurer Edward C. Franklin, Leo H. Baekeland, Wilder D. Bancroft, Frank Hemingway, Chas. H. Herty,}

